\title{
Tecnologias de Informação e Comunicação: Teoria, Interatividade e Prática Profissional
}

\author{
Marcelo M. Teixeira ${ }^{1}$, Marcelo B. C. Leão ${ }^{1}$, William Menezes ${ }^{1}$, Micaías Paiva ${ }^{1}$, \\ Joel Alves de Lima Júnior ${ }^{1}$, Josival dos Santos Silva ${ }^{1}$ \\ ${ }^{1}$ Núcleo SEMENTE - Universidade Federal Rural de Pernambuco (UFRPE) \\ R. Dom Manoel de Medeiros, s/n, Dois Irmãos, Recife-Pernambuco, 52171-900 \\ ${ }^{2}$ Departamento de Química \\ Universidade Federal Rural de Pernambuco (UFRPE), PE - Brasil
}

semente.ufrpe@gmail.com

\begin{abstract}
We present a qualitative and empirical-descriptive research, highlighting the educational technologies used in the educational process by teaching staff of the Faculty Writer Osman Lins da Costa, as well as the projects developed by students of information systems that institution based on subjects taught. Data collection took place from February 2013 to February 2014 in four graduating classes of that course. From this benchmark, we obtained the study sample and, as a result, had a useful overview of the incorporation of educational technologies into the curriculum of FACOL.
\end{abstract}

Resumo. Apresentamos uma investigação qualitativa e empírico-descritiva, destacando as tecnologias educativas utilizadas no processo educativo por docentes da Faculdade Escritor Osman da Costa Lins, assim como os projetos desenvolvidos por alunos do Curso de Sistemas de Informação dessa instituição com base nas disciplinas ministradas. A coleta dos dados ocorreu de Fevereiro de 2013 a Fevereiro de 2014 em quatro turmas concluintes do mencionado curso. A partir desse referencial, obtivemos a amostra do estudo e, como resultado, tivemos um proficuo panorama sobre a incorporação de tecnologias educacionais no currículo da FACOL.

\section{Introdução}

O início do século XXI é caracterizado pela definição dos novos meios de comunicação, globalização, redes de comunicação, usos sociais e políticos das novas mídias, teorias da interatividade, realidade artificial, e os novos rumos da sociedade contemporânea, face a diversidade de dispositivos comunicacionais na Internet, afirma Teixeira (2012). $\mathrm{Na}$ Educação, a introdução das tecnologias de informação e comunicação no processo educativo é aceita por sistemas de ensino em todo o mundo como um epítome do desenvolvimento educacional na história da humanidade e os governos nacionais têm investido massivamente na compra de hardware, software e formação docente contínua, conforme o aparecimento de recursos tecnológicos inovadores. Mediante tantas mudanças na vida em sociedade e no mundo do trabalho, foi preciso reinventar a forma de ensinar e aprender, presencial e virtualmente, devido aos modelos educativos tradicionais estarem cada vez mais inadequados, afirmam Moran, Masetto e Behrens 
(2003). Realidade presenciada no curso de Bacharelado em Sistemas de Informação da Faculdade Escritor Osman da Costa Lins, onde discentes de tal curso utilizam tecnologias educativas na maior parte das disciplinas ministradas e, de igual modo, são estimulados a desenvolverem projetos de inovação com base nos recursos multimídia vivenciados em sala de aula. É nesse sentido que objetivamos, no presente artigo, apresentar um panorama sobre a incorporação de tecnologias educacionais no currículo da Faculdade Escritor Osman da Costa Lins, localizado no Município de Vitória de Santo Antão, em Pernambuco, e os impactos dessa utilização na trajetória acadêmica e profissional dos estudantes. Ainda, destacamos situações práticas envolvendo o desenvolvimento de projetos desenvolvidos por alunos dessa instituição de ensino superior.

\section{Metodologia}

A metodologia adotada é de natureza qualitativa e de caráter empírico-descritivo, norteando-se pelo Estudo de Caso de quatro turmas concluintes do Curso de Bacharelado em Sistemas de Informação da Faculdade Escritor Osman da Costa Lins, onde apresentamos as tecnologias educativas utilizadas professores e alunos da FACOL e alguns casos sucesso profissional com base na utilização dessas tecnologias. A coleta dos dados ocorreu de Fevereiro de 2013 a Fevereiro de 2014 em quatro turmas concluintes do mencionado curso. A partir desse referencial, obtivemos a amostra do estudo e, como resultado, tivemos um profícuo panorama sobre a incorporação de tecnologias educacionais no currículo acadêmico da FACOL.

\section{Resultados}

Empresas têm necessidades de formação, objetivos e estilos de ensino-aprendizagem diferentes, por isso, não existe uma única abordagem metodológica ou modelo instrucional, mas sistemas estruturados com base nos resultados que se pretende alcançar no processo educativo, como revela Teixeira (2013). No decorrer do curso (escolar ou universitário), o educando deverá adquirir competências que servirão não apenas a certificações formativas e profissionalizantes. Ao assunto, adicionam Tapscott e Williams (2010) que a interação global, baseada na partilha de informações e conhecimentos, e os avanços das tecnologias de informação e comunicação, mudaram o conceito de economia e sociedade em diferentes campos do saber: os consumidores tornam-se produtores e os produtores tornam-se consumidores de conteúdos, bens e serviços, em um novo modelo econômico planetário, sem restrições ou barreiras, induzidos por um processo contínuo de colaboração massiva (Teixeira, 2012). Aqui, referenciamos o estudo de caso do Curso de Bacharelado em Sistemas de Informação da Faculdade Escritor Osman da Costa Lins, que utiliza tecnologias educacionais de acordo com as especificidades de cada disciplina, estimulando os alunos a utilizarem tais recursos no processo educativo e a desenvolverem projetos inovadores com base nas funcionalidades dessas interfaces.

$\mathrm{Na}$ prática, citamos três projetos que se evidenciam pelo sucesso do empreendimento - a Cidadania Digital, a Escola Virtual e o NotaFácil, e que hoje tornaram-se empresas prestigiadas: A "Cidadania Digital" representa a utilização de uma plataforma "mobile" a fim de servir como ferramenta social, garantindo eficiência e responsabilidade nas obras por parte dos órgãos públicos e fiscalização da sociedade local, estabelecendo, assim, um conjunto de normas sociais, onde o cidadão tornar-se-á 
um importante ator neste processo. $\mathrm{Na}$ figura 1 , demonstramos a estrututura de funcionamento da Cidadania Digital:

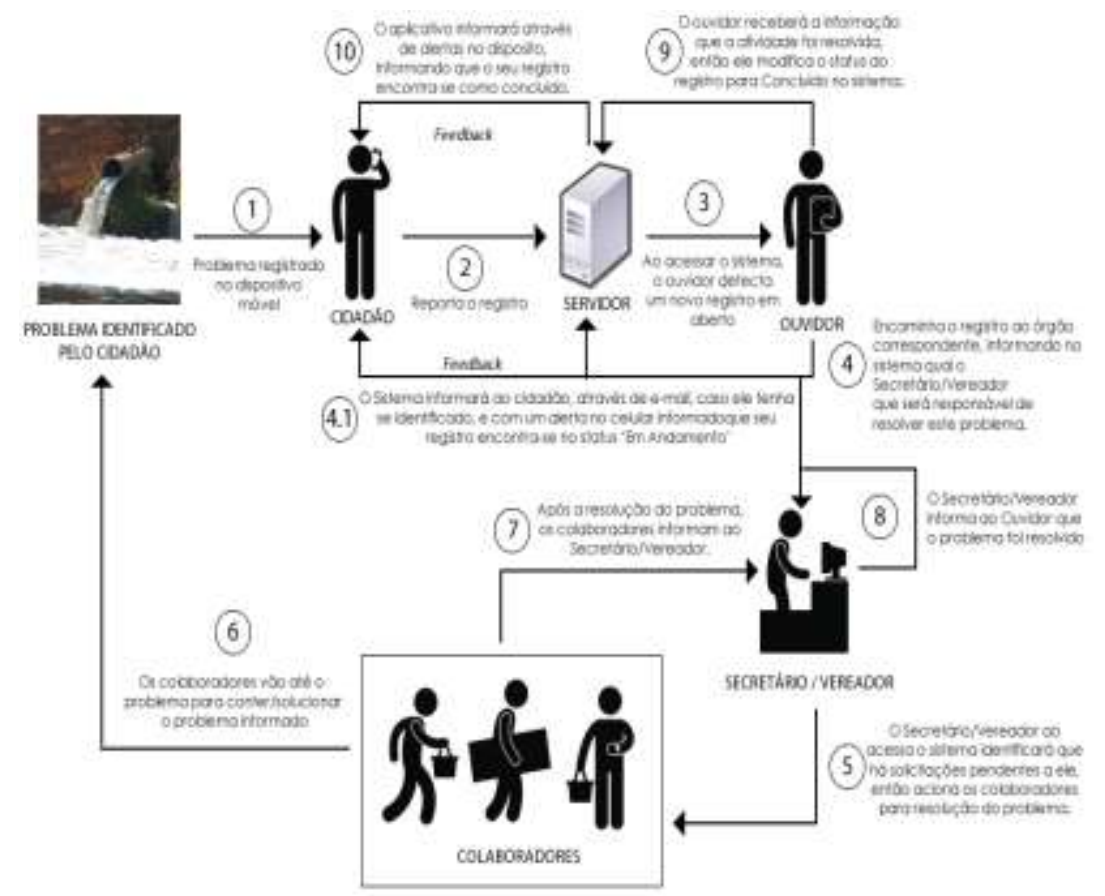

Figura 1. Estrutura de Funcionamento da Cidadania Digital

Os registros de problemas de uma cidade podem ser geridos a partir de plataformas tecnológicas através de dispositivos móveis, auxiliando de forma efetiva no processo de identificação dos problemas de interesse público. O principal foco é a prestação de uma pluralidade de serviços oferecido ao cidadão para que este possa proporcionar a potencialização do exercício de sua cidadania. Tal projeto está em processo de negociação para implantação junto ao Governo do Estado de São Paulo e na Cidade do Recife por meio do Porto Digital. Atualmente, encontra-se em operação no Município de Vitória de Santo Antão, após a parceria firmada entre a empresa do exaluno da FACOL Joel Alves de Lima Júnior e o Governo Municipal.

A Escola Social do Varejo, desenvolvida pelo ex-aluno Micaías Paiva, é o maior programa do Instituto Walmart com foco na causa da Juventude e no Trabalho. Seu objetivo é promover a formação profissional de jovens para o mercado de trabalho varejista para atuarem em pequenas, médias e grandes empresas do ramo. O programa proporciona capacitação para a conquista do primeiro emprego formal no varejo, área que, além de ser porta de entrada no mundo do trabalho, oferece oportunidades de carreira profissional em diferentes modalidades. Assim, a iniciativa do Instituto Walmart combina as competências da empresa à necessidade que a economia brasileira em ritmo de crescimento contínuo, mas carente em mão de obra qualificada. Em 2013, o projeto foi efetivado no Brasil nos Estados do Ceará, Pernambuco, Bahia, São Paulo, Rio de Janeiro, Paraná e Rio Grande do Sul, e em países da América Latina, Ásia e África. A Escola Social do Varejo tem pretensão de ser um modelo de formação profissional para o varejo nacionalmente. Para isso, conta com importantes parceiros locais como organizações não governamentais e secretarias de educação estaduais. Para o desenvolvimento do programa, o Instituto Walmart conta com o apoio do Instituto 
Aliança, uma ONG que acumula larga experiência em formação profissionalizante da juventude brasileira.

Por isso, empreende-se, neste trabalho, uma proposta de implantação e utilização de métodos, técnicas e ferramentas para o cenário educacional online, propondo a utilização de um software educativo que seja capaz de colaborar com a formação educacional de jovens aprendentes do segmento de varejo, objetivando, ainda, o promover uma maior compreensão do mundo do varejo e seus processos produtivos. $\mathrm{O}$ diferencial desse sistema é habilitar e capacitar de forma rápida e dinâmica jovens para entrar no mercado de trabalho, com uma formação específica em software de varejo. Nos Estados de Pernambuco e Ceará, os jovens formados no sistema educacional do varejo recebem uma certificado como curso de extensão, oferecido pela Universidade de Pernambuco e pela Universidade Federal do Ceará. Este certificado, atrelado com outros conhecimentos ofertados pela Escola Social do Varejo, favorece a inserção qualificadas dos jovens no mercado de trabalho em todo o Brasil.

Projetado e desenvolvido pelo ex-aluno Marcelo Wanderley, o NotaFácil tem por objetivo favorecer a mobilidade dos alunos da FACOL para a verificação das notas das disciplinas as quais estão inscritas no período corrente e o cálculo na média atribuída pelo docente (que não é fornecida atualmente pelo sistema de gestão acadêmico da instituição de ensino). A primeira versão do NotaFácil foi lançada para testes no Curso de Bacharelado em Sistemas de Informação da FACOL em Fevereiro de 2013 e, em 2014, entrou em operação sua segunda versão. O usuário faz o "login" fornecendo as informações de matrícula, insere a senha no sistema de gestão acadêmico (Plataforma AcadWeb), e acessa o ambiente a qualquer hora e lugar. Na prática, uma vez selecionada a disciplina na "Tela de Acesso", as Notas exibem o nome da daquela e o valor atribuído (da primeira e segunda unidade, segunda chamada e final), bem como a nota que o aluno precisa alcançar para ser aprovado por média. Tecnicamente, permite interagir em sincronia com utilizadores que disponham de dispositivos móveis com acesso a rede, seguindo o padrão de interoperabilidade "SCORM" ou ontologia. O protótipo inicial do NotaFácil foi desenvolvido em "Javascript" utilizando o "framework Titatium Studio" para dispositivos móveis, e consiste de um servidor "Cloud Computing" para a execução de um "Webservices" escritos em PHP.

Hoje, o NotaFácil funciona em outras três instituições de ensino superior privado no Estado de Pernambuco, além da FACOL, e duas escolas da Região Metropolitana do Recife estão em processo negociação para a sua implantação.

\section{Análise dos Resultados}

Considerando o panorama contemporâneo, convém destacar um conjunto de fatores que influenciam qualitativamente no processo de ensino-aprendizagem e na preparação para o mercado de trabalho entre os alunos do Curso de Bacharelado em Sistemas de Informação da Faculdade Escritor Osman da Costa Lins. É nesse sentido que se faz notória a utilização de interfaces multimídia como recursos de apoio didático, vislumbrando aplicabilidades práticas além dos conteúdos ministrados em sala de aula mediados por tais recursos. Trata-se de um estímulo a criatividade, a interação e a colaboração comunitária não apenas para a área de informática educativa, e os educadores têm consciência dessa realidade, tanto que nas reuniões pedagógicas são discutidas continuamente estratégias de trabalho utilizando tecnologias de informação e comunicação dentro e fora do meio acadêmico. Ademais, existe uma forte preocupação 
quanto a pesquisa e a publicação dos resultados em eventos nacionais, internacionais e em periódicos indexados. Como descrito em epígrafe, alguns dos projetos desenvolvidos estão se tornando empresas de referência em âmbito nacional e internacional, e o curso como um todo é contagiado por essa perspectiva, inclusive, pela possibilidade de ingresso dos alunos em programas de pós-graduação nas universidades federais do Estado de Pernambuco.

\section{Conclusão}

Consideramos que a utilização de tecnologias educacionais no processo de ensinoaprendizagem dos alunos do Curso de Bacharelado em Sistemas de Informação da Faculdade Escritor Osman da Costa Lins proporciona prósperas oportunidades que transitam do meio acadêmico ao mercado de trabalho, e a comunidade estudantil sentese estimulada por seus pares e professores a desenvolvem soluções em TI, muitas vezes, voltadas à Educação presencial e online, como a Escola Social do Varejo. Outro importante aspecto é o reconhecimento das atividades para o cumprimento dos créditos escolares obrigatórios, já efetivamente integrada ao currículo daquele curso. No presente, a instituição de ensino investe na disseminação de tais práticas entre as demais áreas do conhecimento, principalmente nas áreas de saúde e comunicação social através de eventos acadêmicos periódicos, como a ExpoFacol e as semanas comemorativas de cada profissão. É assim que a instituição tornou-se referência de qualidade de ensino no interior do Estado de Pernambuco, com o crescimento vertiginoso do número de matrículas. Por um lado, aspectos como a independência e a autonomia na aprendizagem, a sua personalização e o controle desse processo por parte de quem aprende, desde sempre fundamentais no processo educativo, ganham agora uma nova dimensão e relevância com as novas tecnologias de informação e comunicação, quando a cultura participatória da Internet exige pedagogias, elas também participatórias, em que os aprendentes sejam contribuintes ativos para a sua experiência de aprendizagem. Por outro, a vivência em rede, assente na partilha, no diálogo e na colaboração, requer contextos em que a aprendizagem tenha uma forte dimensão social e a interação e a colaboração sejam incentivadas (Mota, 2009).

\section{Referências}

Aviram, A. (2000). From "computers in the classroom" to mindful radical adaptation by education systems to the emerging cyber culture. In Journal of Educational Change, 1 (4), 331-352.

Silva, B. (1998). Educação e comunicação. Braga: Centro de Estudos em Educação e Psicologia da Universidade do Minho.

Moran, J., Masetto, M. \& Behrens, M. (2003). Novas tecnologias e mediação pedagógica. São Paulo: Papirus.

Mota, J. (2009). Da Web 2.0 ao e-learning 2.0: Aprender na rede. Dissertação de Mestrado. Lisboa: Universidade Aberta de Lisboa.

Tapscott, D. \& Williams, A. (2010). Wikinomics: How mass collaboation changes everything. New York: Penguin Group.

Teixeira, M. M. (2013). Da educação a distância às plataformas de e-learning: sistemas alternativos de educação mediada. Munique: Grin Verlag.

Teixeira, M. M. (2012) As faces da comunicação. Munique: Grin Verlag. 